\title{
O PATRIMÔNIO ARQUEOLÓGICO RUPESTRE NO AGRESTE PERNAMBUCANO: A COMUNIDADE EM FOCO
}

\section{A U TORAS}

\section{Claristella Santos}

claristella@gmail.com

\section{Viviane Maria Cavalcanti de Castro \\ vivianemcc@gmail.com}

\section{Marinete Neves Leite}

netleite@gmail.com
Doutorado em Arqueologia (Faculdade de Letras/UP); Arqueóloga do Núcleo de Estudos Indigenistas (DL/CAC/UFPE).

Doutorado em Arqueologia (PPGA/UFPE); Professora Adjunto 1 do Departamento de Arqueologia da Universidade Federal de Pernambuco.
R E S U M O

A B S T R A C T
Esse artigo tem como objetivo apresentar um levantamento preliminar de alguns dados para nortear o projeto "A educação patrimonial no agreste pernambucano: a comunidade em foco, uma parceria que pode dá certo", que tem como área geopolítica inicial o município do Brejo da Madre de Deus, situado na Mesorregião do Agreste pernambucano. Esse levantamento incluiu uma avaliação prévia do papel do patrimônio arqueológico rupestre para a comunidade local, representada pelos vários segmentos sociais da população brejense. Outro aspecto diz respeito à análise dos impactos antrópicos produzidos sobre alguns sítios arqueológicos rupestres, que foram atingidos por esse tipo de impacto. Essa avaliação embasará ações de educação patrimonial que visem evitar a continuidade de comportamentos lesivos ao patrimônio pré-histórico na área de abrangência do projeto.

Palavras-chave: Educação Patrimonial, Patrimônio Rupestre, Brejo da Madre de Deus.

This article aims to present a preliminary survey of some data to guide the project "The heritage education in the Agreste region of Pernambuco: a community in focus, a partnership that can works", to be developed initially in the geopolitical area of the municipality of Brejo da Madre de Deus, located on the Mesoregion of the Agreste of Pernambuco. This survey included a preliminary assessment of the role of prehistoric archaeological heritage to the local community, represented by the various social segments of the local population. Another aspect concerns the analysis of human impacts produced on some archaeological rock art sites that were affeted by this kind of impact. This evaluation actions form the basis of heritage education aimed at preventing the continuity of behavior detrimental to the prehistoric heritage in the area covered by the project. 
A problemática da preservação do patrimônio rupestre na região do Brejo da Madre de Deus, situado na Mesorregião do Agreste pernambucano, diz respeito às ações degradantes tanto do ponto de vista antrópico como natural. Alguns sítios rupestres na área em estudo têm sido alvo de ações humanas lesivas, especialmente aquelas voltadas para fins de subsistência da comunidade local, através da exploração do granito, favorecendo a destruição de sítios arqueológicos e do seu entorno. Diferentemente dos casos de pilhagem ou saques, que resultaram na dilapidação de sítios arqueológicos, tal como os de Cartagena das Índias, na Colômbia, descrito por Andrade Lima (2007), há em comum a necessidade de sobrevivência, bem como o potencial de mudança de comportamento por meio da educação patrimonial.

Os sítios arqueológicos no Brejo da Madre de Deus estão alijados de um caráter identitário, elemento que deveria configurar um processo natural, mas que, contrariamente, só tem sido despertado a partir do desenvolvimento de um trabalho de educação patrimonial, posto a partir da necessidade não de se resgatar uma memória, mas de contextualizar e mostrar a importância de um patrimônio que, apesar de distante do nosso passado e das nossas realidades atuais, pode servir de entreposto para uma investida com retorno social. Nesse contexto, é importante explicitar que tal retorno diz respeito não apenas à ciência, mas pressupõe que o trabalho de educação patrimonial poderá também redundar, num futuro não muito distante, na participação comunitária em termos de um projeto de desenvolvimento sustentável voltado para o turismo. Paralelamente a isso, prevêem-se, ainda, diversas ações que possam resultar na preservação e na valorização dos bens arqueológicos e, considerando-se as potencialidades locais, a educação patrimonial no Brejo da Madre de Deus deve caminhar ao lado da educação ambiental e considerar outros bens potenciais do município. Assim, "a educação patrimonial e ambiental deve ser conduzida de modo a contemplar a pesquisa, o registro, a exploração das potencialidades dos bens culturais e naturais no campo da memória, das raízes culturais e da valorização da diversidade" (PELEGRINI, 2006: 127).

Diante dessa situação, que não é exclusiva dos municípios nordestinos, iniciamos um programa de ações educativas voltadas a atingir não apenas um segmento da sociedade brejense, como os professores e alunos, mas igualmente um maior número de segmentos sociais, como membros da administração pública do município, caçadores, trabalhadores rurais, proprietários de terra onde há sítios arqueológicos, líderes comunitários, guias locais, motoristas de transporte público alternativo, artesãos e, dentre estes, os escultores em granito.

Esses segmentos sociais supracitados encontram-se diretamente relacionados com o patrimônio rupestre mesmo sem ter uma ligação de identidade e de não o reconhecer como parte de sua cultura. Desse modo, as ações educativas a serem ampliadas visam dois objetivos principais: (1) assinalar as dificuldades consideradas como limitantes à preservação do patrimônio arqueológico pré-histórico, especificando a sua natureza, e (2) ampliar as ações de educação patrimonial, a fim de se obter como resultado a participação da comunidade brejense na preservação dos sítios arqueológicos pré-históricos da região. 


\section{Localização}

A área pesquisada abrange especialmente o município de Brejo da Madre de Deus, além de áreas fronteiriças pertencentes aos municípios de Santa Cruz do Capibaribe, Taquaritinga do Norte, Belo Jardim, Tacaimbó e São Caitano, Caruaru, Toritama e Jataúba (Figura 1).

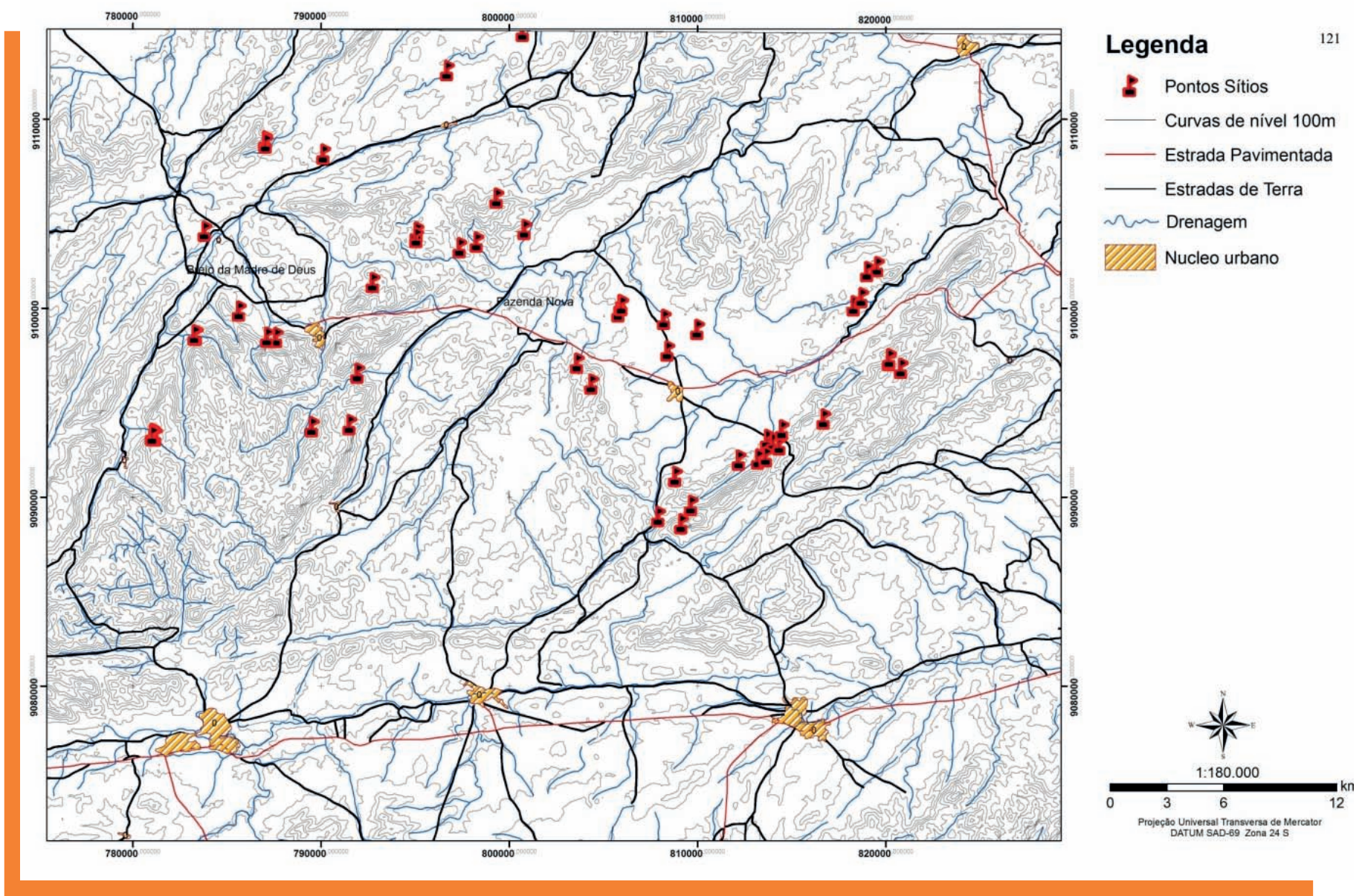

Fig.1: Carta topográfica da área da pesquisa, com a localização dos sítios arqueológicos.Fonte: SANTOS, C. A., 2010.

\section{A problemática da preservação do patrimônio rupestre}

No Brasil, os sítios arqueológicos sempre foram objeto de curiosidade, pois, de um modo geral, exprimem um interesse não só pelo passado humano (uma vez consciente da relação de pertença ao passado), mas pelo incógnito, pelo desejo do leigo de interpretar ou de tentar "desvendar" um "tesouro" perdido. Os sítios rupestres podem ser completamente ignorados ou dar margem a muitas interpretações, sobretudo quando estão associados a enterramentos.

Particularmente no Nordeste do Brasil há, também, uma antiga lenda a respeito da botija, cuja mística ainda prevalece em alguns lugares. Dessa forma, a presença de arqueólogos em cavernas ou abrigos, de um modo geral, desperta a curiosidade da população local, a qual logo a associa a uma possível busca de botija, até que uma explicação convincente seja dada. Essa mística tem levado à destruição parcial ou até mesmo total da estratigrafia de muitos sítios, em decorrência da realização de covas. 
Outra mística refere-se à busca do "carneiro de ouro". A esse respeito resgatamos um exemplo de um sítio arqueológico no município de Buíque, agreste pernambucano, com gravuras rupestres cuja base sedimentar, estratigráfica da furna, foi dinamitada visando à busca de um "carneiro de ouro". Assim, restou apenas um grande painel rupestre, pouco afetado nessa investida, e o contexto arqueológico estratigráfico, no âmbito da furna, ao qual o painel de gravuras podia estar relacionado, desapareceu com a destruição das camadas estratigráficas do sítio.

No Brejo da Madre de Deus a mística da botija também existe, inclusive as pinturas rupestres são interpretadas por um membro da comunidade como uma representação do local onde a botija pode ser encontrada. De modo semelhante, as pinturas rupestres também são vistas como uma manifestação linguística, ou seja, "letras" que compõem um significado, não podendo ser lidas pela população atual. Esses letreiros, os painéis rupestres, são desprovidos de significado identitário enquanto patrimônio que precisa ser preservado.

Os locais onde há pinturas não amedrontam, porém, por outro lado, não Ihes é dada importância na perspectiva patrimonial, mas sim no sentido do senso comum; daí o universo "imaginário" circunscrito nas ideias, na fala e/ou no discurso da comunidade em geral, conforme os exemplos citados (botija e letreiros). Nessa perspectiva, há muitos que até conhecem as pinturas desde a infância, mas não lhes conferem qualquer valor de preservação, principalmente uma conotação patrimonial. Foi dessa maneira, então, que várias informações sobre a localização de "letreiros" foram obtidas e que, em várias conversas informais e longas, nós nos posicionamos perante a população local sobre a importância dos mesmos e da necessidade de sua preservação.

\subsection{A preservação do patrimônio rupestre: memória e reconhecimento}

Manifestações de destruição parcial ou total de sítios rupestres recaem na questão da identidade. Esta, em geral, surge de forma natural, em relação a algo ou alguém, revelando, espontaneamente, uma expressão de reconhecimento (MENESES, 1984).

Em A Memória Coletiva (1990), Halbwachs defende que a memória é formada pelas relações com os diversos grupos com os quais convivemos em nossa comunidade. A memória se apoia na história vivida pelos indivíduos e as lembranças e ideias são geradas no interior dos grupos. Em vários momentos, mesmo que o indivíduo esteja fisicamente só, suas reflexões são coletivas, deslocam-se de um grupo para outro; os indivíduos só lembram pela interação com os outros. Desse modo, para este autor, os outros nos ajudam a lembrar, pois têm lembranças em comum.

O indivíduo só tem capacidade de lembrar quando se coloca no ponto de vista de um ou mais grupos com os quais convive. A memória coletiva mantém sua duração no fato de ter como suporte um conjunto de memórias individuais. Halbwachs afirma que "[...] cada memória individual é um ponto de vista sobre a memória coletiva, que este ponto de vista muda conforme o lugar que ali eu ocupo, e que este lugar mesmo muda segundo as relações que mantenho com outros meios" (1990: 51). 
Contudo, a memória é uma representação seletiva do passado que é de todos os indivíduos inseridos em seus diversos grupos de convivência. Sendo seletiva, os indivíduos só lembram daquilo que ainda está ativo em suas lembranças e do que compartilharam comumente com outros membros do grupo. Desta maneira,

[...] à medida que o cidadão se percebe como parte integrante do seu entorno, tende a elevar sua auto-estima e a valorizar a sua identidade cultural. Essa experiência permite que esse cidadão se torne um agente fundamental da preservação do patrimônio em toda sua dimensão. $O$ conhecimento adquirido e a apropriação dos bens culturais por parte da comunidade constituem fatores indispensáveis no processo de conservação integral ou preservação sustentável do patrimônio, pois fortalece os sentimentos de identidade e pertencimento da população residente, e ainda, estimula a luta pelos seus direitos, bem como o próprio exercício da cidadania (PELEGRINI, 2006: 127).

De fato, há uma forte relação entre patrimônio e identidade, a qual também está associada à cidadania, uma vez que fortalece os laços do cidadão (COPELAND, 2009). O fortalecimento desses laços tem um papel preponderante na valorização e preservação do patrimônio.

Assim, não há dúvida de que o patrimônio arqueológico pode ser elemento de identidade, mas, na maioria das situações, os sítios arqueológicos não estão ativos nas lembranças das comunidades. Em geral, existe uma falta de identificação com o patrimônio arqueológico. Na opinião de Bradford (1998), o cidadão brasileiro não se reconhece e não reconhece este patrimônio como seu, ou como parte da sua história; não há, segundo este autor, nenhuma identificação, e isto é resultado do fato de que o povo brasileiro ignora as suas raízes. Tal afirmação, no entanto, deve ser esclarecida através da descoberta da história do lugar, de modo a se construir um conhecimento do processo que pode ter contribuído fortemente para o distanciamento da população local de suas origens indígenas na região.

\section{A comunidade em foco: metodologia do trabalho de campo}

\subsection{As entrevistas}

No que concerne à realização das entrevistas, optamos por uma amostragem qualitativa. Para as coletas e composição de um banco de dados, foram organizados protocolos de entrevistas específicas para todos os segmentos

1 Há na região do Brejo da Madre de Deus a prática da caça de subsistência, especialmente voltada para o consumo de um pequeno roedor, que vive em locais rochosos ou pedregosos, o mocó (Kerodon rupestris). Os caçadores desse roedor costumam frequentar ou se abrigar em sítios rupestres, fazendo pequenas fogueiras e deixando restos de lixo. sociais que julgamos expressivos, tais como: a administração pública do município; o professorado e estudantes; os caçadores ${ }^{1}$; os trabalhadores rurais; os proprietários de terra; os líderes comunitários; os guias locais; os artesãos; os escultores.

As entrevistas não seguiram uma sequência de perguntas/respostas em forma de questionário, mas um roteiro definido, flexível, e, em função das respostas e do que mais podia ser explorado em cada entrevistado, fez-se uso, inclusive, de uma linguagem acessível, a qual estava atrelada, 
entre outros fatores, ao grau de escolaridade do entrevistado; o uso dessa linguagem mais coloquial contribuiu para fazê-lo compreender o que se estava buscando, havendo, contudo, a preocupação em não induzir a uma resposta. Consideramos, ainda, a categoria do entrevistado, pois nem sempre era possível usar todos os itens do roteiro e alguns outros elementos surgiram espontaneamente ao longo de algumas entrevistas (SANTOS, 2006). É nossa intenção aprofundar este fio condutor da pesquisa em um projeto futuro, de cunho interdisciplinar, cujos resultados têm se mostrado de fundamental importância para um trabalho de educação patrimonial.

\section{$\Rightarrow$ Protocolo de entrevista: exemplo}

- Entrevistador: Por que as pinturas são chamadas de letreiros?

- Entrevistado: [...] a gente chama de letra né , acha que é uma letra, aquilo... foi escrito alguma coisa ali, [...] e dizem, então, o índio chegava ali, ele tinha uma ideia, os que não sabiam, suponho que tenha sido isso.

- Entrevistador: Mas quando o senhor era pequeno, se comentava que as pinturas eram feitas pelos índios?

- Entrevistado: É... sempre achavam que sim, isso era...era da época de índios. Poderia num sê mas é..., porque o índio é..., na minha concepção, foram um dos habitantes daqui da nossa região, né? Teve o índio, depois teve escravo.

\subsection{O registro dos sítios}

Os sítios registrados foram avaliados individualmente, in locu, possibilitando perceber e descrever os principais agentes que vêm contribuindo para sua degradação, tanto em nível antrópico como natural, constituindo elementos suficientes para se refletir sobre o desenvolvimento de uma estratégia de preservação e gestão do patrimônio arqueológico local. Também foi realizado um amplo documentário fílmico e fotográfico de cada sítio. Cinquenta e nove (59) sítios arqueológicos foram visitados e, com exceção de um único com gravuras e outro apenas com sepultamentos, todos os demais são sítios rupestres.

\section{4- Resultados}

\section{- Fatores Impactantes Identificados}

O patrimônio rupestre da área em estudo tem sido alvo de uma série de impactos naturais, dentre os quais destacamos: erosão eólica e pluvial; fixação de ninhos de vespas e galerias de cupins, desplacamento rochoso decorrente da amplitude térmica; desenvolvimento de fungos, liquens, plantas grimpantes e outros agentes biológicos (SANTOS et al., 2007). Esses agentes degradantes naturais são comuns em sítios rupestres e seus efeitos têm sido largamente estudados (LAGE et al., 2004; LAGE, 2007).

Além dos impactos naturais, ressaltamos a degradação do patrimônio rupestre provocada pela ação humana, a exemplo da exploração da rocha granítica para fins comerciais, do uso do suporte rochoso para produção plástica de esculturas (Fotos de 1 a 7) e também da utilização de abrigos e furnas 
por agricultores e caçadores. Estes, por sua vez, contribuem negativamente para o aumento da amplitude térmica quando realizam fogueiras, que de igual modo impactam os painéis através da produção de fuligem, a qual se fixa sobre as pinturas rupestres. Registramos também riscos recentes sobre as pinturas pré-históricas, como restos de construção em alvenaria, pintura com tinta a óleo ou similar, etc.

\section{- Relação Patrimônio x Identidade}

Uma avaliação da história da ocupação colonial no Agreste de Pernambuco nos permitiu constatar que a desagregação dos grupos indígenas que ocupavam a região contribuiu fortemente para o aniquilamento quase que absoluto das raízes ameríndias, restando apenas, no Brejo da Madre de Deus, referências evasivas aos primeiros ocupantes da região. O resultado das entrevistas também nos forneceu subsídios para a conclusão de que inexiste para a população local uma identificação com os sítios arqueológicos pré-históricos. Uma vez inexistente, até onde pudemos averiguar, não há retroalimentação no sentido de resguardar, de preservar o patrimônio arqueológico précolonial (SANTOS, 2010). Portanto, "o que se busca é a tomada da consciência das comunidades sobre a relevância da geração, valorização e resguardo de patrimônios culturais locais" (SABALLA, 2007: 23).

Deste modo, concluímos que a ausência deste vínculo identitário com as materialidades pré-históricas, no caso, os sítios arqueológicos, conduz a uma omissão involuntária no que respeita à preservação. Os suportes das pinturas ou gravuras rupestres, de um modo geral, são vistos como um produto econômico, enquanto matéria-prima a ser transformada. Poucos são os que vislumbram o patrimônio arqueológico pré-histórico local como possibilidade de exploração turística.

Assim, tomando por base a ligação entre patrimônio e identidade (BEZERRA DE MENEZES, 1984), pudemos apreciar de perto, a partir das entrevistas ao longo do trabalho de campo, o quanto essa relação, no município do Brejo da Madre de Deus, encontra-se notadamente distanciada e, desse modo, o caminho a ser trilhado para que a relação entre patrimônio $\mathbf{X}$ identidade se desenvolva deverá ser realmente o da educação patrimonial. Tal conclusão nos faz avançar num raciocínio no sentido de que, uma vez desenvolvido um processo de educação patrimonial, espera-se que a população local assimile a importância do patrimônio arqueológico pré-histórico, tornando-se, deste modo, multiplicadora de uma atitude de valorização e preservação. Contudo, a realidade não é assim. As comunidades só podem entender e respeitar os bens culturais de seu entorno de acordo com a sua história e com as relações que estabeleceram com o passado. Nessa perspectiva, as ações de educação patrimonial são instrumentos que proporcionam um novo olhar para a realidade circundante.

[...] la sociedad es siempre más vieja que esos individuos, de modo que el aprendizaje se vuelve necesariamente hacia el pasado. Propone una educación en la cual se busque no sólo transmitir un saber, sino promover un pensamiento propio, un pensar que se produzca desde la existencia. Es decir que la identidad de una persona sólo se puede entender como relato de su historia, como un proceso de re-apropiación del pasado (CONFORTI, 2010: 110). 
Evidentemente se espera que a educação patrimonial possa conduzir a uma ponderação no sentido de criar nos indivíduos a vontade de conhecer e proteger o patrimônio. Com o seu lugar instituído no âmbito da Arqueologia Pública, a expressão educação patrimonial revela em si a necessidade de ser gerado um conhecimento para um determinado público ou comunidade a fim de que ela possa conhecer, respeitar e valorizar o seu patrimônio. Ou seja, a noção de educação patrimonial, e aqui em particular do patrimônio arqueológico pré-histórico, parte do princípio de que existe um desconhecimento do valor desse patrimônio, sendo necessário, portanto, ensinar que esse bem é significativo, é provido de valor e precisa ser preservado. A necessidade da educação envolve vários fatores, que devem ser analisados de forma integrada. Dentre esses fatores, que devem constituir as bases de um amplo diagnóstico no qual se verifica a necessidade de educação patrimonial, entendemos ser imprescindível a ação do arqueólogo junto à população local, contribuindo, assim, para que esta possa estar mais receptiva às ações educativas a serem empreendidas.

É importante ressaltar, porém, que este processo não funciona quando o valor de pertença é atribuído por outrem; é preciso criar um vínculo afetivo com este patrimônio. Portanto, só a partir desse processo de percepção e de apropriação afetiva em relação aos bens culturais é que os moradores poderão se tornar agentes da preservação, pois já não se sentirão separados do patrimônio, mas sim a ele integrados, com sentimento de pertença e de identidade.

O Patrimônio rupestre do Brejo da Madre de Deus e municípios limítrofes, que têm sido alvo de ações predatórias, revelam a inexistência do sentimento de pertença e de identidade em relação a si mesmos. Dessa forma, é a educação patrimonial, com base no envolvimento de todos os segmentos representativos das comunidades locais, que surge como condição primordial capaz de resultar no reconhecimento e na valorização do patrimônio rupestre da região do Brejo da Madre de Deus.

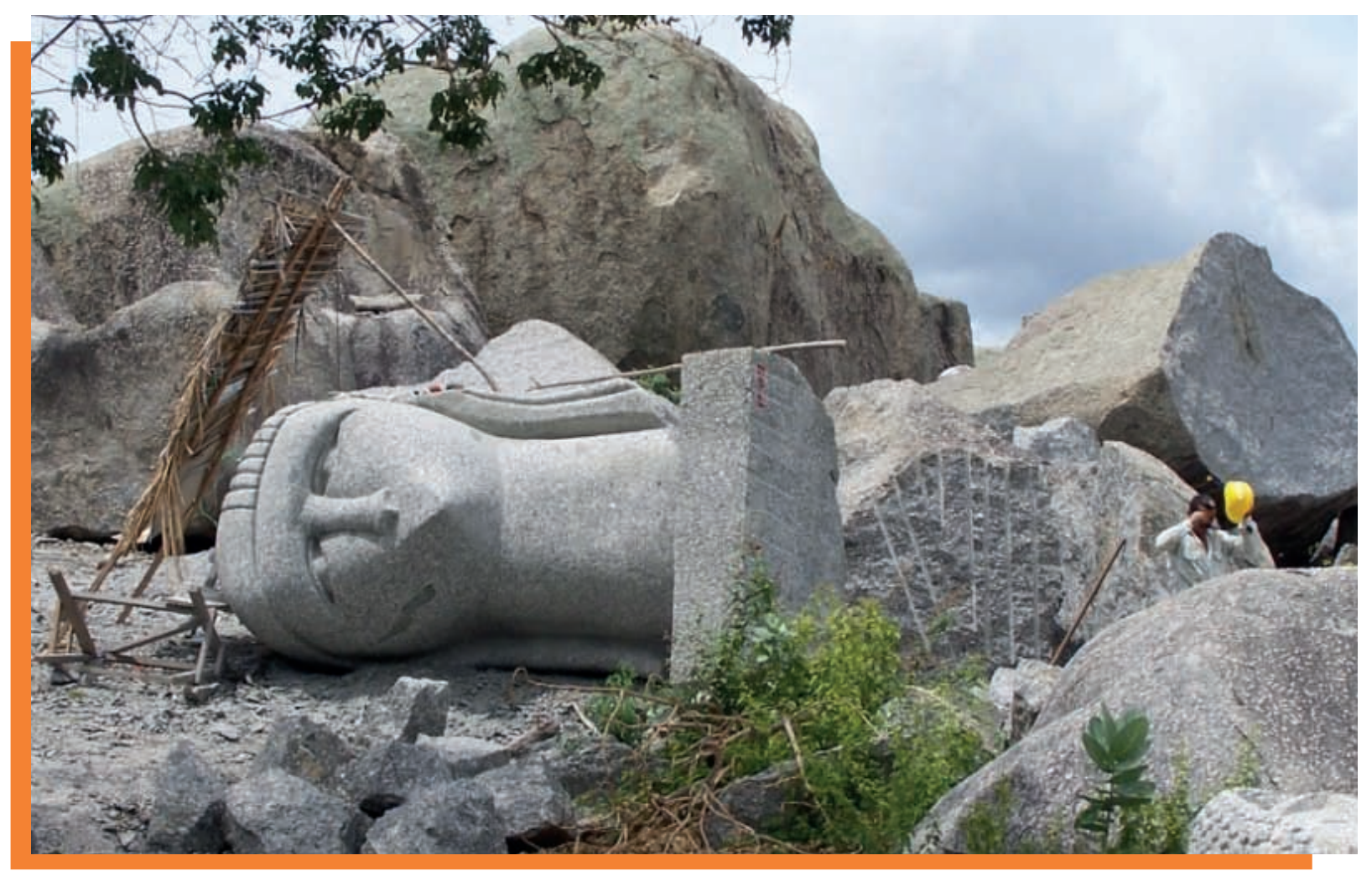

Foto 1: Área do ateliê próxima aos sítios Lagartixa I e II, com uma visão da Vênus de Brassempouy em processo de elaboração. Fonte: Claristella Santos. 


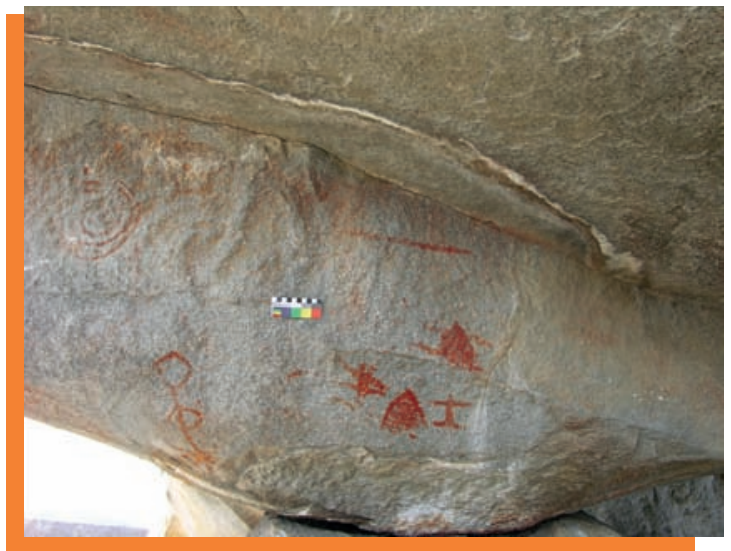

Fotos 2 e 3 - Detalhe das pinturas. Fonte: Claristella Santos. Tratamento computacional: Kátia Oliveira.
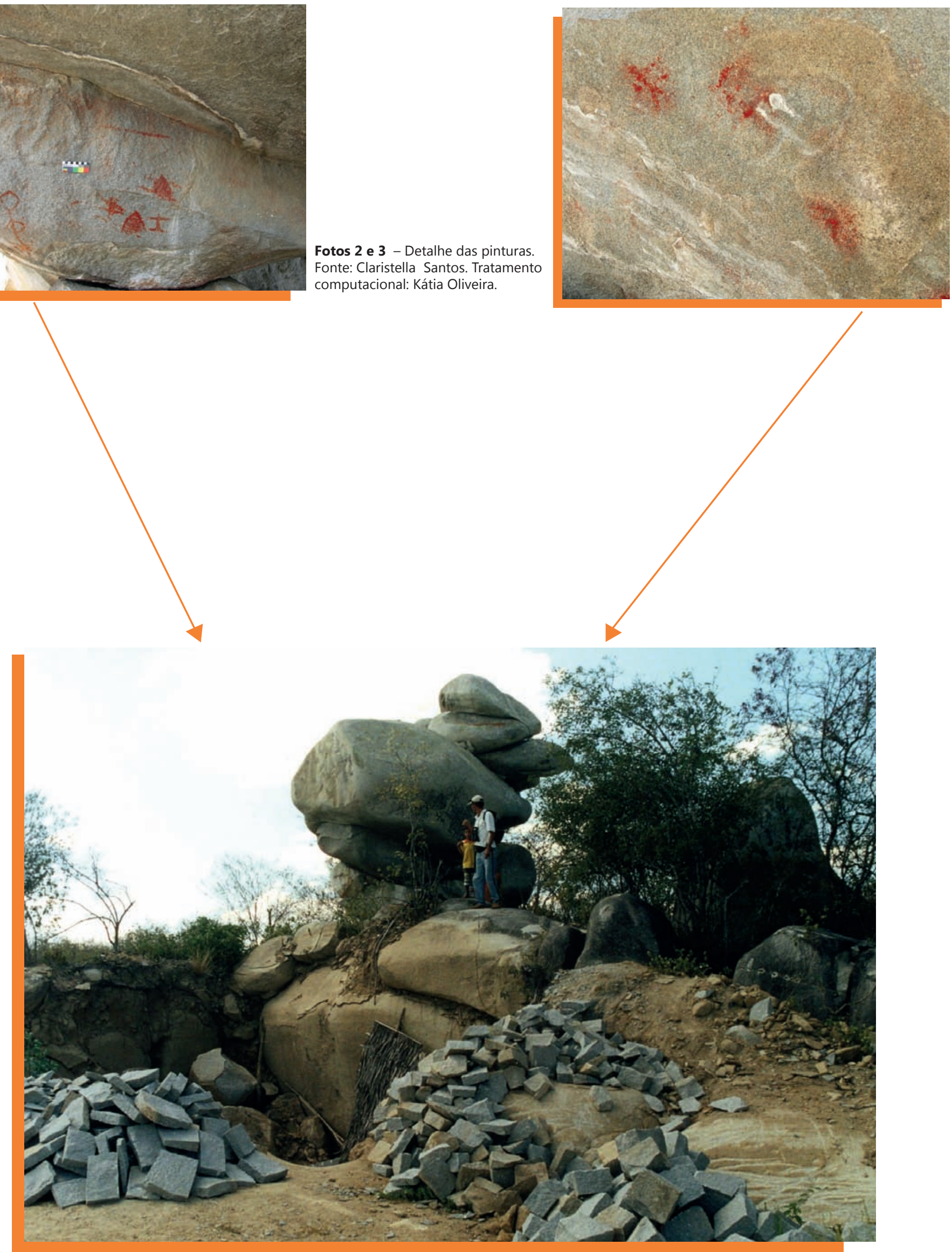

Foto 4: Exploração de granito na Pedra do Brás. Fonte: Claristella Santos. Tratamento computacional: Kátia Oliveira. 


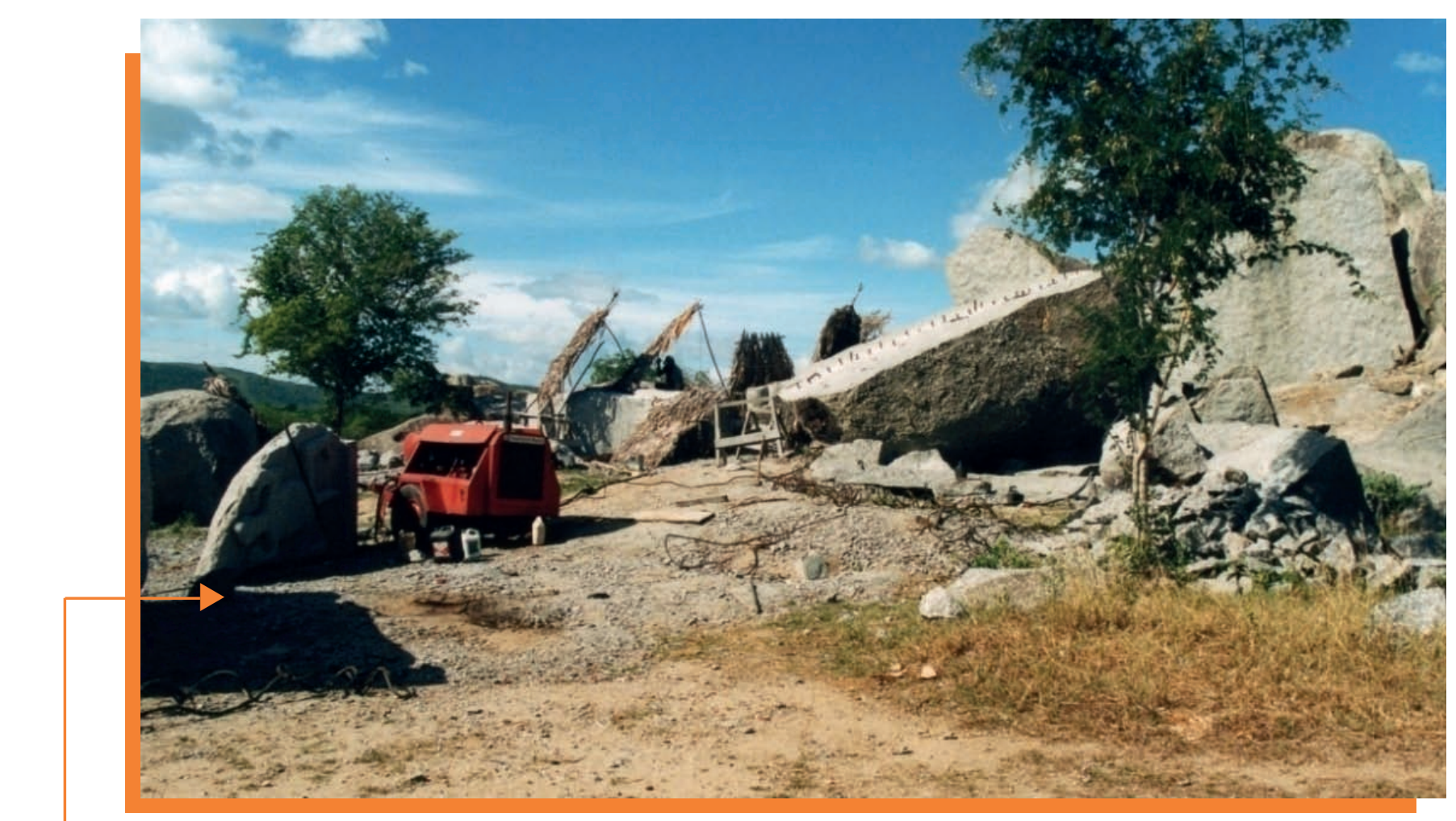

Foto 5: Bloco de granito tombado para a elaboração de esculturas (setas pretas). Parte do bloco com pintura rupestre, que foi repartido (seta vermelha). Fonte: Claristella Santos.

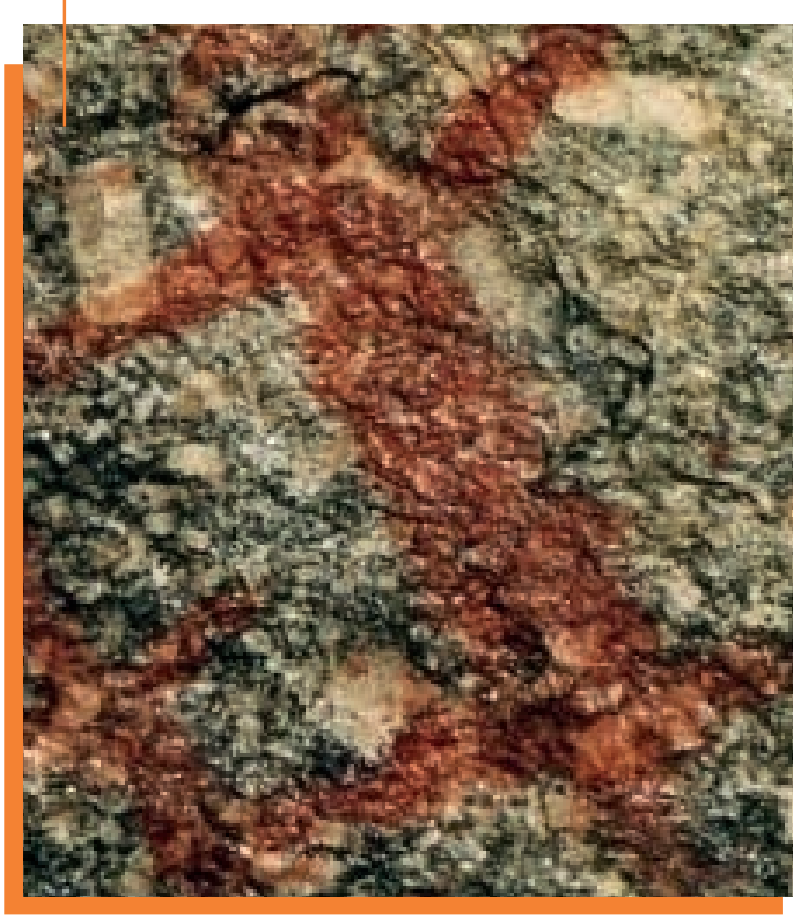

Foto 6: Detalhe da pintura. Fonte: Claristella A. Santos. Tratamento computacional: Kátia Oliveira.

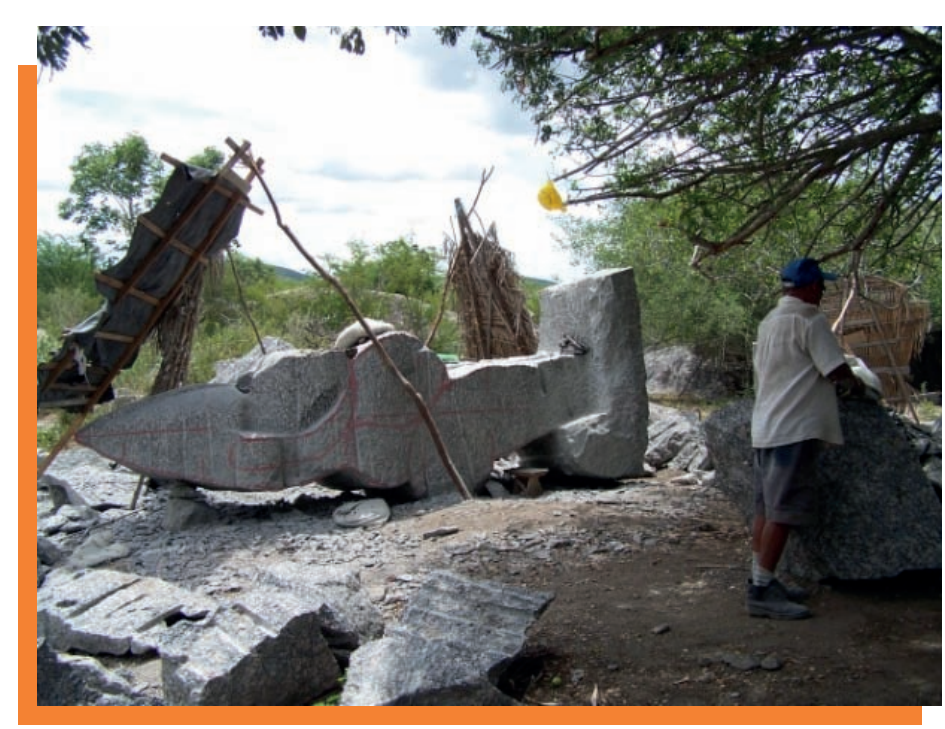

Foto 7: Escultura em processo de elaboração. Fonte: Claristella A. Santos. 


\section{Referências bibliográficas}

ANDRADE LIMA, T. Sobrevivência: a face sensível do tráfico de bens arqueológicos. In: SEMINÁRIO INTERNACIONAL DE GESTÃO DO PATRIMÔNIO ARQUEOLÓGICO AMAZÔNICO, 1, 2007, Manaus. 70 anos do IPHAN, 19372007. Manaus: Instituto do Patrimônio Histórico e Artístico Nacional, Superintendência Regional, 2007.

BRADFORD, R. B. Arqueologia para quem? Monografia (TCC) Faculdade de Arqueologia, Universidade de Estácio de Sá, Rio de Janeiro, 1998.

CONFORTI, M. E. Educación no formal y patrimonio arqueológico. Su articulación y conceptualización. Intersecciones en Antropología. Argentina, n¹1, p. 103-114. 2010.

COPELAND, T. Archaeological Heritage Education: Citizenship from the Ground Up. Disponível em: http://ddd.uab.cat/pub/tda/11349263n15p9.pdf. Acesso em: 13/09/2012.

HALBWACHS, M. A memória coletiva. Tradução de Laurent Leon Schaffter. São Paulo: Vértice, 1990.

LAGE, M. C. S. M. Proteção ao material arqueológico e etnográfico: A conservação de sítios de arte rupestre. Revista do Serviço do Patrimônio Histórico e Artístico Nacional, Rio de Janeiro, n. 33, p. 9-30. 2007.

LAGE, M. C. S. M.; BORGES, J. F.; ROCHA JÚNIOR, S. Sítios de registros rupestres: monitoramento e conservação. Mneme, Revista de Humanidades, vol. 6, n¹3, p. 28-51, dez.2004/jan.2005.

MENESES, Ulpiano T. Bezerra de. Identidade cultural e arqueologia. Revista do Patrimônio Histórico e Artístico Nacional. Rio de Janeiro, n² 20, p. 33-36. 1984.

PELEGRINI. S. C. A. Cultura e natureza: os desafios das práticas preservacionistas na esfera do patrimônio cultural e ambiental. Revista Brasileira de História. São Paulo, vol. 26, n 51, p. 115-140. 2006.

SABALLA, V. A. Educação Patrimonial: "Lugares de Memória". Revista MOUSEION, Canoas, vol. 1, p. 23-25, jun. 2007.

SANTOS, C. A. dos. O patrimônio arqueológico pré-histórico do Agreste pernambucano: fronteiras de valorização. Relatório de pesquisa, nível doutorado, apresentado ao CNPq. 166 p. Brasília, 2006.

SANTOS, C. A. et al. A preservação de sítios rupestres no Agreste de Pernambuco (Brasil): uma análise petrológica. In: CONGRESSO ARGENTINO, 2; CONGRESSO LATINOAMERICANO DE ARQUEOLOGIA, 1., 2007, Buenos Aires. Buenos Aires: Talleres Gráficos Centro Atómico Constituyentes, Comisíon Nacional de Energía Atómica, p. 58-59. 2007.

SANTOS, C. A. dos. O Patrimônio arqueológico pré-histórico do Agreste de Pernambucano: fronteiras de valorização. 2010. 328f. Tese (Doutorado em Arqueologia) Faculdade de Letras da Universidade do Porto, Porto, 2010. 